\title{
Authors and Contributors in Scientific and Medical Publications
}

\author{
Subir Kumar Das ${ }^{1}$
}

Published online: 8 January 2016

(C) Association of Clinical Biochemists of India 2016

Publications are primarily a means of communicating scientific information to colleagues, but they are much more than that. Publications in peer reviewed journals are proof of academic competence, and are used as a crucial component in evaluation criteria for academic promotion and fund raising. These also increase the prestige of academic institution [1]. Earlier, the single-author article was the rule. People used to associate one paper, or idea, with one name; for examples: the production of the first vaccines and Edward Jenner, the discovery of penicillin and Alexander Fleming, and the application of radiotherapy and Marie Curie. But over the past decades, the average number of authors on scientific manuscripts has drastically increased [1].

The role and definition of authorship in scientific and medical journals has become increasingly complicated in recent years. In most other forms of publishing, such as social sciences, humanities, legal, perhaps three or four authors collaborated in the writing of the work [2]. But, the nature of scientific research and reporting means that "authorship" no longer justify into this category [2]. This means, a researcher who didn't write the text of a paper, but contributed substantially to the conception of the work, or the analysis of the data, can still be considered an author. Moreover, electronic communication has made sharing information and collaborating on projects far simpler, and many authors can now work closely with colleagues in different parts of the world. With such a rise in

Subir Kumar Das

drsubirkdas@yahoo.co.in

1 Department of Biochemistry, College of Medicine \& JNM Hospital, WBUHS, Kalyani, Nadia, West Bengal 741235, India collaboration and co-authorship in academic writing, it becomes difficult to differentiate between a "contributor" and an "author" [2].

The debate over authorship and contributorship was again resurfaced in recent past [3], when a paper was published on the genomics of the fruit fly with over 1000 listed authors [4]. Researchers often face dilemmas about authorship, particularly, when the researchers are graduate students, fellows, or junior faculty. The dilemmas might involve discussions about fair criteria for more senior faculty to be acknowledged as key contributors or authors on manuscripts [5]. Though some authors wish to acknowledge the important contribution of their colleagues, but ghost authors are undesirable. Readers do not want a meaningless list of names, they want to know who is chiefly responsible. Such growing trend is a challenge for the editors of journals in the field of bioethics to enhance awareness about the value and definition of authorship [1].

International Committee of Medical Journal Editors (ICMJE) has introduced updated authorship criteria that are widely accepted and most commonly referred. Accordingly authorship credit should be based on (1) substantial contributions to conception and design, or acquisition, analysis or interpretation of data; (2) drafting the article or critically revising it for important intellectual content; and (3) final approval of the content to be published, (4) agreement to be accountable for all aspects of the work, including queries related to the accuracy or integrity of any part of the work [6]. Though some researchers are of opinion that these guidelines are unfairly strict, but they were created to safeguard the idea of authorship to signify scientific integrity [7].

According to Barthes' theory, if the "author" is the representative of his or her institution, or academic background, then all those directly involved in its creation 
should be included [3]. Each person, including undergraduate student, who has contributed to the analysis of data, is also one of the major tenants of authorship according to the ICMJE. If it is assumed that the author is the predecessor of the article, then logically each co-author contributed to the authorship of the paper, however small [2]. This has opened up a dilemma of first authorship. Further, the identity of each co-author eventually becomes considered into the first author when a paper is cited with the use of "et al." [2]. Therefore, some journals have started to implement "Author Contributorship Badges", indicating the role of each individual, in place of, or in addition to, traditional lists of authors [8]. Thus potential roles in the creation of an article are represented by different badges, such as "Data analysis," "Methodology," and "Writing Review." Each badge has a list of authors who contributed to that specific role, and an author can be listed under more than one role [9].

When a large, multi-center group has conducted the work, the group should identify the individuals who accept direct responsibility for the manuscript. These individuals should fully meet the criteria for authorship defined above. Acquisition of funding, collection of data, or general supervision of the research group, alone, does not justify authorship. A Five-step Authorship Framework [10] is designed to create a more standardized approach when determining authorship for industry-sponsored clinical trial publications, which include;

Step 1: Establish an authorship working group early in the trial,

Step 2: Determine substantial contribution criteria,

Step 3: Document trial contributions,

Step 4: Determine those making a substantial contribution, and

Step 5: Ensure authors meet remaining authorship criteria.

Overall, these recommendations aim to facilitate more transparent authorship decisions and help readers better assess the credibility of results and perspectives of the authors for medical research more broadly [10].

Groups of persons who have contributed materially to the paper, but whose contributions do not justify authorship may be acknowledged under a heading such as "clinical investigators" or "participating investigators," and their contribution could be described as-"served as scientific advisors," "critically reviewed the study proposal," "collected data," or "provided and cared for study patients." Financial and material support including a Department Chair, who has provided only general support, should also be acknowledged [2].

Unfortunately, many journals do not provide consistent guidance about authorship and many editors are therefore missing an important opportunity to improve the accuracy, fairness, and transparency of author listing [11]. With evolving concept of authorship, most of the editors of Indian medical journals must upgrade their instructions to authors to include ethical requirements.

\section{References}

1. Borry P, Schotsmans P, Dierickx K. Author, contributor or just a signer? A quantitative analysis of authorship trends in the field of bioethics. Bioethics. 2006;20(4):213-20.

2. Fairbairn S, Kelly L, Mahar S, Prosée R. Authorship: an evolving concept. In: Health learning, research \& practice. Wolters Kluwer. www.wolterskluwer.com.

3. Woolston C. Fruit-fly paper has 1,000 authors. Nature. 2015;521(7552):263.

4. Leung W, et al. Drosophila muller $\mathrm{f}$ elements maintain a distinct set of genomic properties over 40 million years of evolution. G3: Genes, Genomics Genet. 2015;5(5):719-40.

5. Syed S, Tran DQ, Kemper AR, Geme JW 3rd, Lantos JD. Authorship concerns and who truly owns a research idea? Pediatrics. 2015;136(5):969-73.

6. Defining the role of authors and contributors. Int Comm Med J Ed. http://www.icmje.org/recommendations/browse/roles-andresponsibilities/defining-the-role-of-authors-and-contributors. html.

7. Scott T. Changing authorship system might be counterproductive. BMJ. 1997;315(7110):744.

8. Wager E. Recognition, reward and responsibility: Why the authorship of scientific papers matters. Maturitas. 2009;62(2): 109-12.

9. http://www.biomedcentral.com/presscenter/pressreleases/2015 $1001 \mathrm{~b}$.

10. Marušić A, Hren D, Mansi B, Lineberry N, Bhattacharya A, Garrity M, Clark J, Gesell T, Glasser S, Gonzalez J, Hustad C, Lannon MM, Mooney LA, Peña T. Five-step authorship framework to improve transparency in disclosing contributors to industry-sponsored clinical trial publications. BMC Med. 2014;12:197.

11. Wager E. Do medical journals provide clear and consistent guidelines on authorship? MedGenMed. 2007;9(3):16. 